This item was submitted to Loughborough's Research Repository by the author.

Items in Figshare are protected by copyright, with all rights reserved, unless otherwise indicated.

\title{
Barriers to women's access to decision-making positions in sport organizations: the case of establishing a girls' volleyball academy in Israel
}

PLEASE CITE THE PUBLISHED VERSION

http://dx.doi.org/10.1080/09589236.2015.1111835

\section{PUBLISHER}

(c) Taylor and Francis

\section{VERSION}

AM (Accepted Manuscript)

\section{PUBLISHER STATEMENT}

This work is made available according to the conditions of the Creative Commons Attribution-NonCommercialNoDerivatives 4.0 International (CC BY-NC-ND 4.0) licence. Full details of this licence are available at: https://creativecommons.org/licenses/by-nc-nd/4.0/

\section{LICENCE}

CC BY-NC-ND 4.0

\section{REPOSITORY RECORD}

Betzer-Tayar, Moran, Sima Zach, Yair Galily, and lan P.D. Henry. 2019. "Barriers to Women's Access to Decision-making Positions in Sport Organizations: The Case of Establishing a Girls' Volleyball Academy in Israel". figshare. https://hdl.handle.net/2134/19703. 
Barriers to Women's Access to Decision-Making Positions in Sport Organizations: The Case of Establishing a Girls' Volleyball Academy in Israel

\footnotetext{
Dr, Moran Betzer Tayar, Director of the Wingate Academy for Sport Excellence, Wingate Institute, Faculty of Economics and Business Administration, Ruppin Academic Center, Israel.

Dr. Sima Zach - Head of the School of Education at the Zinman College of Physical Education and Sport Sciences, Wingate Institute, Israel.

Prof. Ian Henry - Director of Olympic Studies Centre, School of Sport, Health and Exercise Sciences, Loughborough University, UK

Dr. Yair Galily - Senior Lecture and Researcher at the Sammy Ofer School of Communications, Interdisciplinary Center (IDC), Herzilya, Israel
}

\section{Introduction}

There is a tendency to separate sport from analytical investigation, whether by trivializing it as simply entertainment or valorizing it as a grand expression of so-called national or universal values. In keeping with the critical tradition of sociological investigation of sport, Travers (2009) highlighted the role that the sport nexus plays in promoting and perpetuating gender binaries by culturally and economically marginalizing women and non-normatively gendered people. This is in line with Western culture, which has traditionally viewed gender as a binary concept. Much of the critical work on gender and sport, and its role in reinforcing orthodox masculinity and perpetuating sexism, has failed to challenge the sex-segregated structure of sport itself. The current study sheds light on an innovative, significant policy initiative toward gender equity in sport by analyzing discourses relating to the actual experience of key actors, via both interviews and auto-ethnographical accounts, in establishing a Volleyball Academy for Young Talented Girls (VAYTG) in Israel.

Despite claims that women have broken through the glass ceiling and are now gaining entry into professions that were once the sole preserve of males (see Burke and Vinnicombe 2005), very few women still hold senior-level and executive management positions in major corporations (Lee-Gosselin et al. 2013). Women continue to face barriers to career advancement, including gender stereotyping (e.g., Berkery et al. 2013; Powell et al. 2002; 
Schein 2007), male-dominated organizational cultures (e.g., O’Neil et al. 2008), and corporate traditions that favor men (e.g., Oakley 2000; Powell 2012).

It has been argued that sport is one of the most hegemonic social institutions in modern society in relation to gendered cultural practices (Whisenant et al. 2002). The current underrepresentation of women in sport leadership positions is deeply rooted in the production and reproduction of this hegemony. Under-representation of women in senior administrative positions in sport organizations is a persistent feature of the changing sports scene in many countries, as well as in international sport organizations (Acosta \& Carpenter 2002, 2006; Shaw \& Penney 2003). Therefore, a broader gender-equity policy may be required to bring about a change in the current situation.

Sport organizations often promote traditional gender roles, and male privilege and dominance (Claringbould \& Knoppers, 2007; Knoppers \& Anthonissen 2008). Therefore, it is not surprising that women are still under-represented in leadership positions and marginalized in the sport workplace (Acosta \& Carpenter, 2006). Furthermore, sport organizations' leadership positions are historically linked with sex-role stereotypes (Sartore \& Cunningham, 2007).

Gendered roles in leadership and management are viewed through language, social practices, and policies. These may create gender relations that favor masculine over feminine styles within sport organizations (Shaw \& Slack, 2002) and discursively construct gender roles in the boards of sport organizations. As Shaw and Hoeber (2003) argued, gender roles sometimes illustrate a common belief that leadership roles in sport organizations entail assuming characteristics associated with dominant forms of masculinity. For example, there may be a norm of time and energy commitments beyond job and time requirements in societies in which women are expected to deal with both domestic and public responsibilities. Men are regarded as having fewer family responsibilities, so can invest more time and energy 
in public responsibilities beyond their formal jobs (Hovden, 2000). The tendency of men to occupy influential positions in sport organizations is natural and mostly unquestioningly accepted (e.g., Knoppers and Anthonissen 2008; Pfister 2006). Several researchers observed that senior management roles are heavily dominated by masculine discourse (e.g., Shaw and Frisby 2006). In contrast, women and feminine discourse are associated with roles that are less valued.

However, potential resistance to these discourses exists on a number of levels. Various attempts to focus on increasing the number of women in management positions tried to challenge this unequal situation in sport organization management (Shaw and Hoeber 2003). Figures from studies commissioned by the International Olympic Committee (Henry et al. 2004; Henry and Robinson 2010) indicate a meager representation of women and only a small increase in women's involvement in senior management (e.g., Hoeber 2007; Knoppers and Anthonissen 2008; Moore et al. 2010; Roper 2012).

According to Aitchison (2005), looking at sport organizations' environments helps in understanding why women are less likely to succeed, while men can succeed without equity policies in place. Women's and men's perspectives on managerial positions in sport organizations might imply key differences. Women may not expect recognition in volunteer roles, which are vital for many sport organizations. Men expect and receive public reward and recognition, even as volunteers (Shaw and Hoeber 2003). In that sense, the discourses on masculinity are influential within sport organizations and undermine the discourses on femininity (Knights and Kerfoot, 2004). For example, masculinity is often associated with aggression, strength, competition, and determination required for a successful playing career and a sport-management career after retirement.

Aggressive expressions of masculinity are valued because they are often considered synonymous with dominant forms of leadership (Whisenant et al. 2002). On the other hand, 
women are typically associated with femininity, which may include cooperative work practices or negotiation skills that are largely undervalued and considered chaotic and irrational (Shaw and Hoeber 2003), which have no place in the development of rational organizations.

Researchers suggest that women who adopt masculine discourses are perceived as people who can adapt to the social hierarchy and access power (e.g., McNay 2000; Pfister 2006). Women who want to succeed in an environment dominated by masculine discourse may embrace some masculine work practices. Given their historical construction, these discourses become influential and are problematic to challenge (Adams et al. 2010; McDowell and Schaffner 2011; Shaw and Slack 2002).

Dealing with socially and historically constructed effects of dominant masculine practices seems to be a part of women's everyday condition in male-dominated institutions (Cunningham and Sagas 2008). While traditional practices may be highly influential, they may be changed by individuals willing to create alternative knowledge about gender power structures that are taken for granted. These power relations are not always stable and may face resistance from those who prefer traditional, masculine-dominated gender relations (Shaw \& Slack, 2002). Therefore, understanding the roles associated with the governing of sport organizations is essential for developing necessary strategies to implement genderequity policies regarding women's' representation in leadership positions (Ahlam Hassan and Forster 2011; Barmao 2013).

This study explores an innovative, significant policy initiative toward gender equity in sport by analyzing interviewees and auto-ethnographic discourses relating to key actors' experience in establishing a Volleyball Academy for Young Talented Girls (VAYTG). ${ }^{\mathrm{i}}$ The study addresses the following questions: What are the barriers to women's access to decisionmaking positions in sport organizations? How are these barriers constructed? To what extent, 
and how, were these barriers overcome? The auto-ethnographic account of the first author is central to this purpose. She gradually occupied an important position within the Israeli Volleyball Association (IVA) and played a key role in the decision-making processes within the IVA Board of Administration. She also worked with other key players in the IVA, such as the leading actors that initiated the VAYTG with her.

\section{Method}

Interviews and an auto-ethnographical investigation of the first author's experiences were both applied in this study. ${ }^{\mathrm{ii}}$ Auto-ethnography is a story that reenacts an experience through which people find meaning and reconcile themselves to that experience. It can include research, writing, a story, or a method that connects the autobiographical and personal to the cultural, social, and political elements (Ellis 2004). Auto-ethnography was used because the first author of this paper was a key figure in this case, as the only female member of the IVA board at the time that the VAYTG was inaugurated.

This study reframes the narrative voice. According to Ellis (1997), evocative autoethnography does not question if narratives precisely convey how things actually were. Instead it tells what narratives do, their consequences, and to what uses they can be put. In that sense, female and (some) male executive members of sport organizations are not a homogenous group. Although many share the same interest in the love of sport, they may differ in terms of class, race, sexual identity, age, disability, body size and cultural, religious and linguistic heritage (Dewar, 1993). To some extent, this is reflected in the different life stories and experiences of key actors in executive positions in this research. This approach provides a narrative that can be subjected to critical discourse analysis (CDA). In this case, it focuses on the interviewees thoughts regarding the organizational processes and gendered discourse relating to roles and barriers for women in Israeli sport organizations. CDA (de)constructs perceptions and attitudes that exist within the IVA. CDA is interested in how 
language and meanings construct and maintain dominant gendered discourse. Bloor and Bloor (2007) note that discourse achieves social goals and performs a role in social maintenance and change.

We do not claim that gendered discourse is the only barrier to equity. We argue that by illuminating the significance of language in classifying people with respect to their place in historically contextual power structures and socially constructed powerful groups (some men) or less-powerful groups (some women), we can clarify how language maintains gender inequities in the Israeli sport context. Furthermore, Shaw (2001) noted that enlightening individuals' perceptions of gendered issues can promote the idea of resistance as emancipatory. This provides a starting point for this research, as it highlights the potential to challenge discriminatory power relations.

Research site selection was influenced by the theoretical argument that gender power relations are identified and constituted through discourse (Hovden 2012; Thomas and Rugambwa 2011). The personal experience and involvement of the first author within the IVA was a considerable advantage in understanding the sociohistorical context, the gendered discourses and organizational sets of values, and the barriers women encountered in gaining access to executive positions. The development of the case study in cooperation with coauthors offered the opportunity to test and challenge the evidential basis for the claims made on the basis of the analysis of her own discourse about her experience.

\section{Interviewees}

For the purposes of this paper, much of the data was derived from a set of interviews undertaken with four male respondents who played significant roles in, or observed, the development of the VAYTG. The interviewees were chosen by their position level and perceived influence and familiarity in the IVA. A further criterion was their reported involvement in establishing the VAYTG and the associated decision-making procedures in 
the IVA. Three were national and international coaches (two with the Volleyball Academy), and the other was the most internationally successful Israeli coach. The first interviewee was the men's junior national coach, a top-level player in Israel and a first-division and national team coach for men and women. He led the establishment of the Boys Volleyball Academy and supported establishing the VAYTG. The second interviewee was the girls' junior national coach and the Girls' Academy coach. He was a former top-level player and still was active (second-division) when he started coaching at the Academy. The third interviewee was a successful coach for 15 years in the top Japanese league and won two silver Olympic Medals as a coach with the Dutch men's national team in Barcelona (1992) and with the US women's national team in Los Angeles (1984). He came back to Israel to establish a national senior women's volleyball project. The fourth interviewee was a member of the Technical Commission, a former top-level player in Israel, and the national team coach. For many years, he was involved in developing the Israeli volleyball infrastructure. He was a member of the small group that led the volleyball academies for boys and girls in Israel.

The discourses in this paper raise the voice of those in the IVA at that time. Most of the IVA board members and members of the IVA senior staff, including the first author, were secular Jewish Israelis. Most were ethnically Ashkenazi (Jewish with a maternal lineage largely derived from Central and Eastern Europe), and there were no Israeli Arabs. This socially constructed homogenic organizational environment might have helped the first author become a board member, despite being female.

\section{Interviews}

We explored discourses within the IVA, which the interviewees used to describe their ideas, experiences, and conceptions of life, as well as their ideas on Israeli equity policies within Israeli sport organizations. The interviews were undertaken following the first author's own 
auto-ethnographical account. She was the first female member of the IVA Executive Board and the only female member until 2008.

\section{Auto-ethnographical Account}

The supporting pillar of this study is an auto-ethnographical account that represents her story as the first female executive in the IVA. The account was analyzed with regard to the cultural context within which her story took place. It was constructed mainly in relation to M's professional life story at the time it was written and did not focus on her other roles as mother, wife, daughter, kibbutz member, and secular Jewish Israeli. This was partially because she was less aware of the impact of her personal life story and its relation to her professional identity and role at that time. Her story focused on the processes in which she was involved and by which she was influenced, and eventually led to the establishment of the VAYTG in 2003.

In this account, we replaced validity concerns with warrantability, effectively emphasizing truth as a criterion. By using an auto-ethnographic method, we tried to provide opportunities for readers to identify and learn from these life experiences and perspectives, and gain insight into and understand their own life experience. In effect, the author's own account will be judged in much the same way as her analysis of the interviews against how plausible, coherent, and authentic her account appears to be.

CDA methodology was used in this study to explore how dominant gendered discourse helps maintain power structures and support gender inequities (among others). Furthermore, using CDA provides many potential benefits for the feminist ${ }^{\mathrm{iii}}$ approach in understanding and challenging gender inequities in Israeli sport organizations. Potter and Wetherell (1987) point out that the use of linguistic resources to solve a particular problem will often create new ones. However, the appearance of new problems and solutions can help interpretations of the original usage. The linguistic device recognizes inconsistency and deals with the problems it 
creates. Furthermore, treating new problems also tends to unfold more sequentially than treating contradictions. Bloor and Bloor (2007) suggest that speakers sometimes assume a shared understanding that does not exist. In such cases, communication may break down.

After the open-ended interviews, each of which was recorded upon agreement of the interviewees, full transcripts were prepared. We then inductively identified emerging and repeating themes of the critical descriptions, such as barriers, gender ideology, perceptions of the VATYG project, and perceptions on the role of female actors in the national federation (NF). We then sorted themes into analytical categories of discourses, such as homogeneity, assertiveness, need of knowledge about political power in sport organizations, fear of otherness, socializing through masculinization and/or men's code behavior, and painful concessions that provided the basis for discussing the findings in this study.

\section{Results and Discussion}

Women remain under-represented in sport organizations (Spoor and Hoye, 2014). Male culture is an often-cited reason for the relative lack of female senior managers. Knoppers \& Anthonissen (2008) note that little research has explored how that culture is created and managed by men doing and thinking masculinity, and the role that images of athletic masculinities play in that.

Consequently, our analysis of the interviews and the auto-ethnographical account identified six main themes related to the research questions regarding barriers women experience and how they are constructed.

(1) A gender balance. All IVA board members were male, who had a shared ethnic background. Most were born and raised in Israel as secular Ashkenazi Jews. This might have made it easier for a woman of that ethnic identity to enter the Board, rather than a Sephardic Jew (descended from Jews who lived in the Iberian Peninsula or North African countries) or 
a Muslim female in such a conservative gender order (Knoppers and Anthonissen 2008). M noted that she felt like a pioneer:

Breaking into the male decision-makers' circles was like a mission of a pioneer, paving the way for other women.

No women had been there before. She had to be very determined in order to change this one-gender homogeneous structure of the Board. Similarly, Interviewee \#1 asserted:

I think that to some extent one of the reasons for the IVA Board's unintentional tendency not to invest in women's volleyball, is the lack of women in decision-making positions...men tend to support men's sport.

(2) Political wisdom. M had to manage within the political context of the IVA board to promote her ideas and major initiation of establishing the VAYTG. She also had to identify the intentions of external stake-holders within the macro-governmental organizations and gain support from the Ministry of Culture and Sport to have more influence and build a supportive network. M concluded that in order to create a large, revolutionary project and relate to gender equity within an NF, an external influence was required. Moreover, she had to explore the extent of power each board member was able to exercise, as well as the interpersonal relationships among the members that could assist her in breaking into the male decision-makers' circles.

During the forthcoming months, we started the process of mapping the forces within the board and the related stake-holders. I felt it would be useful to know which members were in favor, against, or undecided. I was aware of the power of the people who were present at the meeting and their influence on the decision-making processes within their organizations and the Israeli sport arena. I also became familiar with power relations within the Ministry of Sport and understood with whom I could move things forward. (M's auto-ethnographical account).

The process of acquiring knowledge and understanding regarding these political issues took time and effort when adjusting to the organization's everyday life (Pflieger et al. 2005). M worked closely with experienced people, mainly from the technical staff, who guided her through the labyrinth of the power relations within the IVA Executive Board. Interviewee \#4 recalls: 
During our chats, I tried to tell you some of the different layers of connections that I thought I was familiar with. I believed that if you knew this you would be able to understand with whom it would be possible to lead a positive decision regarding the VAYTG projects.

(3) Fear of otherness. Such a fear is a sense of threat from the uncertainty of new different members, or from new ideas and voices that must be challenged in a deconstruction of the Executive Board's secure world. However, one interviewee suggested that female players had also contributed to the situation of women's volleyball in Israel by lacking the determination to demand greater equity:

The problem of discrimination in women's volleyball comes from both directions; from male key holders, but also from the girls and women themselves. I don't see a lot of young girls with ambition and motivation to change the situation or to be the best in their area ...women need to come and demand. (Interviewee \#2)

Or, another example:

In my opinion, female athletes don't want enough. They want us to invest in them, but then they don't want to push. They don't believe in themselves. With men, it is not the same. (Interviewee \#1)

This quote demonstrates a clear imputation of the inferiority of female athletes, not by virtue of biological difference but by their level of commitment. This might be one of the main barriers to women's access to decision-making, as it leaves a thin line between following the dominant socially constructed expectations from an athlete and sport director and keeping one's unique values, perceptions, and behavior. It is a subjective judgment for each woman to decide where that limit is, and how far she is willing to go:

As the only female member on the IVA board from 1998 until 2008, I sensed that fear of other in the Board, which resulted in my continually feeling the need to prove myself in order to gain respect and acceptance from my male counterparts. (M's autoethnographical account).

Blaming women contributed to the continued marginalization of women's volleyball by the IVA Executive Board. This approach reflects what Martin (2003) characterized as a practice that men can adopt by believing their actions are not gendered, so that they can truly deny that they act in a gendered manner during decision-making processes. 
(4) Code of behavior. To bring a gender-equity policy to the organization, more women's voices need to be heard among the decision-makers:

I still remember the first meeting in which I participated, when one of the male members asked me to bring the coffee...I felt 12 pairs of eyes staring at me and assessing my reaction. (M's auto-ethnographical account)

I think you were at the beginning of your journey, and you were on your own, and frankly we had a mutual interest. Nonetheless, your status was not so strong, so they might have tried to manipulate you, but they wanted to show that they had the power: we will tell you what is what, we know better...I believe they did it not against you personally, but because they wanted to show that they had the power, not you. (Interviewee \#1)

Furthermore, in order to be accepted and influential, $\mathrm{M}$ intentionally adopted some agenetic characteristics that, according to Eagly and Johannesen-Schmidt (2001), are masculine such as assertiveness and independence. This decision caused an ongoing conflict when $\mathrm{M}$ wanted to maintain her other characteristics, such as affection or interpersonal sensitivity, but felt that highlighting them would identify her as the other and limit her influence.

Humor was one of the key communication tools used in board meetings. M thought that she must adopt this style of communication to become influential within its dominant masculine discourse, with jokes often relying on gender stereotypes. Another difficulty was the necessity to be present and active in different commissions of the Board, at events, meetings, and conferences in different parts of the country, invariably outside working hours. She had to be involved in informal discussions and decision-making processes and meetings, and use the language of the male decision-makers. Moreover, she took part in their social events, stayed late in the IVA offices, and took part in unofficial activities with the other key actors. $\mathrm{M}$ was frustrated that even after a long period of all this hard work, she did not feel that she was an integral part of the round table in the IVA boardroom:

I could not say that I was one of the guys. Moreover, I know that I do not want to become one of them. I want to stay myself, with my beliefs and values. (M's auto-ethnographical account) 
A significant barrier related to the process of socialization through masculinization is that women early in their careers may not wish to be like men (O’Connor 2001). They may prefer to avoid involvement in decision-making positions in sport organizations. Other women may see it as a challenge to bring their own characteristics and set of values into the organizational culture (Sealy 2010; Yeganeh and May 2011).

(5) Assertiveness. One way to be respected and be taken seriously by the male-based Executive Board was speak assertively and exhibit strength and determination during the process of establishing the VAYTG. An example of this took place during an important meeting:

After a lengthy meeting, I was shouted at by a senior executive. I stood up and said that I was not prepared to tolerate this kind of behavior, and left the room...After a while, I received a phone call from him, asking for my forgiveness. I returned to the board, feeling more confident this time. (M's auto-ethnographical account)

And on another occasion:

I stood up and gave a speech for about 10 minutes about stereotyping women and sport, and ended with a little joke about men. Everybody knew to whom I was referring. This was a very important event, and I discovered later that the other Board members learned to appreciate me more. This may have been because I played by their rules. I showed power, and understood later on that this was one of the unwritten rules that must be followed if one wants to break into the male circle, professionally and socially. (M's autoethnographical account)

This action resulted from the ongoing need to address the aggressive attitudes of M's male counterparts in the organization, which she perceived as denigrating and promoting a nonsupportive gendered atmosphere in the closed surroundings of the IVA. M declined to engage in a confrontational approach, but explained her rationale of why this masculine behavior was unacceptable. After she became a Board member, some former female volleyball players wondered why she would subject herself to that kind of behavior:

My friends who used to play volleyball with me on the national team asked me what I was doing there with all the politicians, as they said that they [the male members] would never invest anything in women's volleyball. (M's auto-ethnographical account) 
Indeed, some men in IVA executive positions did not appear to perceive female colleagues in the same way as they did their male colleagues. This manifested in a number of ways, such as fear of the other, insecurity, or a chauvinistic attitude towards women. However, this was expressed as suspicion, and a perception of women as lacking a serious, settled approach toward their activities. As a result, the men tended to reject initiatives put forward by female executives, regardless of relevance or merit. Therefore, $\mathrm{M}$ adopted a strategy that let her stand up for her beliefs and values and to also be accepted by her colleagues as a professional and an expert in their historically and socioculturally constructed perspective on this area of expertise. $M$ was assertive and confident, but nonetheless aware of the informal relationships she had identified within the IVA Executive Board.

M gradually sensed a growing acceptance of her perspective among some of the male members. The more influential she became, the more the underlying realities of the gender struggle became apparent. The respectful limits and informality of debate were rejected by some of the IVA members who were not persuaded by her efforts, and male responses became more explicit, direct, and personal:

But you are a woman representing women...so they might have tried to intimidate you if you were doing the same but with men, I don't think they would have tried to do it to you.

These continuing, seemingly endless struggles on gender issues and the ongoing need to prove herself as a legitimate board member brought into play another barrier to women's access to decision-making positions. Women's assertiveness can also lead to a situation in which they may be unpopular with some men and become socially isolated. On the other hand, it is also possible that when a woman behaves assertively in a male-dominated environment, she may gain respect and acceptance. In such circumstances, her voice will be heard and may be more influential in the discursively constructed contexts within the organization. M described this process: 
I knew I had gained an enemy, but I did not know what would happen with the other members. However, I felt happy that I had confronted him, and had stood up for my values. Later on, I received many phone calls from people who had witnessed the incident. Some said that it was very good; some said that I should not have left the room, but all of them were supportive. (M's auto-ethnographical account)

At that point $\mathrm{M}$ realized that if she wanted to make a meaningful contribution to the organization, she must gain more support both for herself and for the issue of gender equity. Gaining more support, even from influential outsiders, might help M become an influential figure within IVA decision-making processes and help put the issue of gender equity on the organization's agenda:

I believe that this meeting was the most important point of the process, firstly because the discussion was now not just confined to the board room but was somewhat within the public domain. Secondly, people realized that I was not a toy that was there for decorative purposes. (M's auto-ethnographical account)

Assertiveness, which was identified as an important tactic adopted to achieve influence as a woman in a male-dominated organizational board, may be associated with assimilation of a wider range of masculine behaviors (Budworth \& Mann, 2010; Ekaterini, 2010). This process of assimilation may engender a more fundamental masculinization of female members. M's merely achieving some goals by behaving in accordance with her values (that were more ascribed to feminine behavior), accompanied by some characteristics more often ascribed to masculinity, did not mean that she was an integral part of the round table. In that sense, both approaches might have negative consequences. The other might remain an isolated outsider or become part of the dominant network of male members, risking diminution or contamination of the unique female voice. This unpalatable choice may reinforce women's hesitation to seek access to decision-making positions in sport organizations:

I came to a decision to become part of the male network, without giving up on my values. This was based on the fact that there seemed no way to win the fight when there was only one woman within the association. (M's auto-ethnographical account) 
This decision required self-awareness and discipline to manage within the board, and was perceived by some interviewees as having strengthened M's position:

When I started the job, you were already there (on the NF board)...you took care of us...distanced us from politics...it was and still is a kind of safety net for those who are dealing with women's volleyball. (Interviewee \#2)

(6) Making concessions. During progress toward a final decision to develop the Academy, M made painful concessions to clinch support for the project. At a certain point, people began to realize that this project could be established. When the Board needed to make a concrete decision regarding the VAYTG, some interesting discourses arose that, whether intended and/or explicit, or unintended and/or implicit, threatened to delegitimize the project. Some of the Board related the project to M personally and did not see it as an IVA initiative:

I knew that any problem I'd come across, I have somebody to go to. I'm not sure I could carry on in this kind of project otherwise. For example if they had sent us some member of the board (like they did) without the commitment you had as a life project, I'm not sure the whole project would have survived. (Interviewee \#2)

The explanation is that "You (M) brought about the project," and "you (M) were its major proponent and defender," rather than the project being an outcome of considered discussion.

Nonetheless, many IVA members realized that if the VAYTG was accepted, it would be quite expensive. This might mean less money available for men's volleyball and related activities:

The other barrier was the Ministry of Sport. They had never invested that amount of money in team sport, and therefore it caused many budgeting problems. Regarding the girls' project specifically, the message was that if we add them to the project it will reduce the amount of money the boys have. Actually, that is what happened in the first stage because the budgets stayed almost the same and they didn't double the budget when the girls entered the academy. (Interviewee \#1)

M was expected to continue to act according to the cultural rules of the male-dominated board. In this case, the unwritten rule was "You get some, you give some." In other words, she had to give back something to the key actors who promised to help establish the VAYTG. She was asked to give up on an important issue related to gender equity, which meant conceding her position and values to achieve her main aim: 
An offer from one of the most influential figures within the volleyball association was that 'In order to find a way to continue the processes,' he suggested postponing all other activities of women's national teams for the following two years, with the exception of the $V A Y T G$, to make this project a reality. This suggestion was the 'Catch 22 ' of the project...It was presented as this, or nothing, and as the only one who really wanted it to happen was me, I needed to take this unfair decision by myself. (M's auto-ethnographical account)

This, perhaps more than any other aspect, illustrates the implicit discourse wherein women's volleyball was not considered a natural part of the IVA's concerns. Nevertheless, in order to justify this move, M had to believe that without it, the VAYTG would never be approved. Furthermore, according to interviewees' perceptions of this act, the male board members precipitated this Catch 22 situation, because they did not actually want an expensive prestigious project for women:

The requirement to stop any other women's activity was because they didn't want the project for women, and they tried to do whatever they could to prevent the project. (Interviewee \#1)

To some extent, $\mathrm{M}$ assumed they gave her this proposition as a test to see how far she was willing to go. Nonetheless, it was an opportunity to explore who might (or might not) be in favor of the project. For example, the use of the word they in the previous quotation might imply that Interviewee \#1 saw himself and $\mathrm{M}$ on the same side. In this case, the idea of postponement of any other women's national team activities (although seemingly inappropriate) for a relatively short period of time was preferable to giving up on the VAYTG project. The project had the long-term potential to positively and significantly change Israeli women's volleyball for the future. In the end, the long-term view paid off. Encouraging insights.

The second aim of this study was to study how the identified barriers might be overcome by (some) women and (some) men in decision-making positions in Israeli NF's. Drawing on the interviews and the auto-ethnographical account yielded some encouraging insights regarding gender equity in sport organizations. From M's ethnographical account we conclude that 
establishing the VAYTG was partially based on the perception that by supporting the needs of both genders, it might open a way for young sportswomen to aspire to the top. This idea was supported by others:

I believe that the female players in the VA have already changed...if we want them to be competitive athletes and to aspire to reach for the stars, we have to start at an early age, not more than 13-14...Moreover, since we have joined the VA, I don't think the girls are discriminated against in comparison with the boys. (Interviewee \#2)

In a broad view, $M$ used strategies to create empathy toward her, such as from those in a speech she gave to the IVA Board and senior representatives from clubs of the first division of the league:

At the beginning of my speech, I noticed that many people in the room were not listening; some had left and some were talking among themselves. Subsequently, I changed my plan and delivered a speech that started with my own feelings, my dreams that never came true as a player, and asked them to see instead of me, their daughters, wives, or sisters. When I was sure that they more or less had focused on me, I started to tell them about our plans. (M's auto-ethnographical account)

Another strategy was developing the discourse of sisterhood. In addition to the official and unofficial actions within the IVA, M developed some other informal contacts with women who were willing to help. Perhaps the most significant of these was with a specific woman within the Ministry of Culture and Sport. Other supporters included leading figures at the Wingate Institute for Physical Education and Sport and within the Israeli Women's Sport Foundation. These connections were very helpful in developing the project, mainly by influencing the male-dominated IVA Board and Board of the Ministry of Culture and Sport:

It was something new, and for them [the IVA members], dealing with a women's network was clearly a new experience. That was a winning point at the creativity stage.

Furthermore, it looked as though the women's network had demonstrated power, something these men were familiar with, and it was therefore more acceptable for them to vote for a women's project. (M's auto-ethnographical account)

M felt that the women's network she created helped her become influential in the maledominated environment and that she was not alone in her struggle. In addition, it helped her understand the informal relationships of outsiders with the Board and other sporting 
organizations. Furthermore, these outsiders unconsciously provided $\mathrm{M}$ with mentoring guidance, in the form of being experienced figures within the sporting arena. $\mathrm{M}$ also used informal connections with various females in key positions in other national organizations to gain more inside information regarding the different perceptions of key people in relation to the VAYTG. Even within this network, she had conflicts based on each person's different feminist views:

When I asked the female members of the Israeli Women Sport Foundation for their opinion regarding the postponing of other female activity, they were immediately against it. They said I should not do that, saying that it was not worth it. I was confused, and tried to explain the rationale for the long term, but they still stuck to their opinion, and even said that they would end their support for the establishment of the VAYTG and in some ways, for me. It meant they would not support me. (M's auto-ethnographical account)

Whatever the reasons why the other women disagreed with M's decision, they decided to take a step back, so were no longer closely involved in the project. Finally, with the involvement of the formal representative of the Ministry of Sport, led by one of the female members of her network, the decision was made to locate the VAYTG at the Wingate Institute, along with the boy's VA.

The idea behind the VAYTG was that, for the first time in the history of Israeli volleyball, a national team for girls and a national team for boys would receive the same treatment, resources and conditions, according to their specific needs. This was probably essential in achieving the successful implementation of the project, since $M$ was the sole female and active proponent of the project. Although the situation has improved with the opening of the VAYTG, promoting a discourse of gender equity still has a long way to go.

In outlining the process of establishing the VAYTG, this paper explores the unwritten rules and underlines the realities of the IVA. As M was the only female on the Board, she thought that she had to fit in with the male-dominated board to change the existing gendered discourse. However, M had to maintain her self-identity, values, dedication, assertiveness, and persistence to preserve her female voice (e.g., Fine 2009; McNae, 2010). To avoid being 
steered into an unwelcome environment in the volleyball political arena, $\mathrm{M}$ tried to keep the target she was struggling to achieve and the reasons for it, within her sights. In many cases, some men perceived women as threatening outsiders and tried to keep them away from the nerve center of the decision-making process. She found that if she wanted to deconstruct the context of hegemonic masculinity within the IVA, she must preserve the beliefs and values preventing her from assimilating into the existing hegemonic discourse on the IVA.

This study had some limitations. First, attempts to recruit interviewees who opposed establishing the VAYTG were unsuccessful. Therefore, all interviewees represented a favorable attitude toward the VAYTG project. Nevertheless, by exploring the perspectives of male interviewees who supported the project. we still identified negative discourses against equity. However, presenting the opponent's voice might have resulted in more and/or other insights regarding the questions at hand. Second, the research's theoretical post-structural feminist approach brought about the author's story is allegedly an inherent bias. Nevertheless, this limitation can also be a strength (Attride-Stirling, 2001; Bazeley, 2009). Nobody, except an individual inside the organization, could understand the nuances that $\mathrm{M}$ detected regarding nonverbal messages, political power, and codes of social behavior. Moreover, an outside researcher (the second author) reviewed the transcripts of the interviews and M's account, and analyzed their content. Discrepancies were discussed until an agreement was reached, so that validity was achieved by increasing trustworthiness.

By examining the sometimes flexible relationship between masculinity and femininity, we examined how some women gained and maintained senior positions by adopting masculine styles. However, female expression of masculinities is not straightforward. While women in sport organizations may engage in masculine discourse in their employment roles (Shaw and Hoeber, 2003), women who express masculinities may challenge assumptions about what is acceptable behavior for women. 
This study demonstrated that the presence of women in decision-making positions in sport organizations is a necessary, although not sufficient, condition for generally promoting and developing sport, and specifically women's sport. It was evident from the interviews and M's account that, at some point, establishing the VAYTG probably totally depended on her fights and determination for it to come into being. The process was not easy, with so many barriers along the way (M's auto-ethnographical account).

The International Olympic Committee, a number of national Olympic committees, and several international federations accepted that the minimum targets for 2005 should be 20 percent female membership of their boards. Many countries, including Israel, have legislation regarding women's representation on the boards of their sport organizations (Galily and Betzer-Tayar, 2014; Tamir and Galily, 2010; Zach and Adiv, 2015). However, inequalities and barriers to progress still exist. The existing gendered discourses in the IVA (also Federation) both reflect and ensure the fact that equity has not been achieved.

\section{Some Implications for Practice}

In 2014, the International Working Group on Women and Sport (IWG) celebrated its 20th anniversary. Since 1994, the IWG has been a platform to give voice to women and girls across the globe. Through an active network of decision-makers, politicians, researchers, educators, students, coaches, athletes and volunteers, womens' and girls' voices have been shared at conferences, seminars, parliaments, and offices. Tarja Halonen, Patron in Chief of the 6th IWG World Conference declared:

The language of sport is international. Its message touches, awakens feelings and unites. Its world produces inspiring people and phenomena that serve as role models and examples to young people and children. Sport has the power to tell stories that stay in our minds and hearts. Women and Sport (IWG, 2013).

Examining five recent legacies of the IWG, Adriaanse and Claringbould (2014) argue that gender in relation to sport leadership was mainly constructed on the dimension of production and power relations (more women in leadership positions) and symbolic relationships 
(creating a sporting culture that values women's participation at all levels). By contrast, the gendered dimension of emotional relationships, such as collaboration between men and women, received limited attention. Although establishing a collaborative global network for women and sport has inspired and empowered women, a strategy of proactively including men is also required:

Without losing sight of the importance of supportive relationships among women, we recommend that the network be extended to incorporate more men - in particular, influential men who can use their positions to bring about change (Adriaanse \& Claringbould 2014:17).

Through one female voice, this study attempts to explore the experience of developing a gender-equity initiative in a specific organization (IVA) and understand how she overcame the discursively constructed barriers. The implications provide the reader with a unique point of view and analysis, rather than claiming one correct world view.

As long as women continue to be merely a significant minority at the top of the leadership ladder, their voices may be marginalized and their sociocultural status may be discursively constructed as the other, in relation to the norm for the male-dominated boards of executives. Therefore, both women and men must strive for gender balance in sport organizations, so that each gender's rights will be maintained and promoted. In addition, women who plan to become influential within decision-making processes of sport organization should consider some of the following insights from this study: (1) Be persistent and dedicated to their missions; (2) the sisterhood discourse might be also be helpful in similar situations; and (3) women might need to assimilate the equity discourse by themselves and live in accordance with their beliefs and values. Women and men can each contribute their unique characteristics to the organization's values, whether female-, male-, or dual-gender based. In a broader perspective, the journey toward change and gender equity in sport organizations is best started at young age. This can occur through education and socialization that deconstruct 
existing contextual sociohistorical structures, beliefs, and values about feminine and masculine discourses, and emphasize the value of equity in general.

\section{References}

Acosta, R. V., \& Carpenter, L. J. (2002). Women in Intercollegiate Sport: A Longitudinal, National Study: Twenty-five Year Update, 1977-2002. Brooklyn, NY: Brooklyn College, Department of Physical Education.

Acosta, R. V., \& Carpenter, L. (2006). Women in Intercollegiate Sport: A Longitudinal, National Study: Twenty-nine Year Update, 1977-2006. Brooklyn, NY: Brooklyn College, Department of Physical Education.

Adams, A., Anderson, E., \& McCormack, M. (2010). Establishing and challenging masculinity: The influence of gendered discourses in organized sport. Journal of Language \& Social Psychology, 29, 278-300.

Adriaanse, J. A., \& Claringbould, I. (2014). Gender equality in sport leadership: From the Brighton Declaration to the Sydney Scoreboard. International Review for the Sociology of Sport. Advanced online publication, Sept. 1, 2014. DOI: 1012690214548493.

Ahlam Hassan, A. M., \& Forster, N. (2011). An exploratory study of the under-representation of emirate women in the United Arab Emirates' information technology sector. Equality, Diversity and Inclusion: An International Journal, 30, 544-562.

Aitchison, C. C. (2005). Feminist and gender research in sport and leisure management: Understanding the social-cultural nexus of gender-power relations. Journal of Sport Management, 19, 422-442.

Attride-Stirling, J. (2001). Thematic networks: An analytic tool for qualitative research. Qualitative Research, 1(3), 385-405. 
Barmao, C. (2013). Overcoming the causes of under-representation of women in primary school leadership in Eldoret municipality, Kenya. Journal of Emerging Trends in Educational Research and Policy Studies, 4, 38-46.

Bazeley, P. (2009). Analysing qualitative data: More than 'identifying themes'. Malaysian Journal of Qualitative Research, 2, 6-22.

Berkery, E., Morley, M., \& Tiernan, S. (2013). Beyond gender role stereotypes and requisite managerial characteristics. Gender in Management, 28, 278-298.

Bloor, M., \& Bloor, T. (2007). The Practice of Critical Discourse Analysis: An Introduction. London: Hodder Education.

Budworth, M., \& Mann, S. L. (2010). Becoming a leader: The challenge of modesty for women. Journal of Management Development, 29, 177-186.

Burke, M. (2001). Sport and Traditions of Feminist Theory (Doctoral dissertation). Victoria University, Victoria, BC, CANADA.

Burke, R., \& Vinnicombe, S. (2005). Advancing women's careers. Career Development International, 10, 165-167.

Chang, H. (2008). Autoethnography as method: Raising cultural consciousness of self and others. In Walford G. (Ed.) Methodological Developments in Ethnography (pp. 207-221). Walnut Creek, CA: Emerald Group Publishing.

Claringbould, I., \& Knoppers, A. (2007). Finding a 'normal' woman: Selection processes for board membership. Sex Roles, 56, 495-507.

Cunningham G. B., \& Sagas, M. (2008). Gender and sex diversity in sport organizations introduction to a special issue. Sex Roles, 58, 3-9. 
De Sensi, J. T. (1992). Feminism in the wake of philosophy. Journal of the Philosophy of Sport, 19(1), 79-93.

Dewar, A. (1993). Would all the generic women in sport please stand up? Challenges facing feminist sport sociology. Quest, 45(2), May, 229-211.

Eagly, A. H., \& Johanessen-Schmidt, M. C. (2001). The leadership styles of women and men. Journal of Social Issues, 57, 797-781.

Ekaterini, G. (2010). The impact of leadership styles on four variables of executive's workforce. International Journal of Business and Management, 5, 3-16.

Ellis, C. (1997). Evocative auto-ethnography: Writing emotionally about our lives. In G. T. William \& Y. S. Lincoln (Eds.), Representation and the Text: Re-framing the Narrative Voice (pp. 115-139). State University of New York Press.

Ellis, C. (2004). The Ethnographic I: A Methodological Novel About Auto-ethnography. Walnut Creek, CA: AltaMira Press.

Fine, M. G. (2009). Women leaders' discursive constructions of leadership. Women's Studies in Communication, 32, 180-202.

Galily, Y., \& Betzer-Tayar, M. (2014). Losing is Not an Option! Women's Basketball in Israel and its Struggle for Equality (1985-2002). The International Journal of the History of Sport, 31(13), 1694-1705.

Henry, I. P., Radzi, W., Rich, E., Theodoraki, E., \& White, A. (2004). Women, Leadership and the Olympic Movement. Loughborough, UK: Institute of Sport and Leisure Policy, Loughborough University and International Olympic Committee.

Henry, I. P., \& Robinson, L. (2010). Gender Equity and Leadership in the Olympic Bodies: Women, Leadership and the Olympic Movement 2010. Lausanne, Switzerland: 
International Olympic Committee and Centre for Olympic Studies \& Research, Loughborough University, UK.

Hoeber, L. (2007). Exploring the gaps between meanings and practices of gender equity in a sport organization. Gender, Work and Organization, 14(3), 280-259.

Hovden, J. (2000). Gender and leadership selection processes in Norwegian sporting organizations. International Review for the Sociology of Sport, 3, 82-75.

Hovden, J. (2012). Discourses and strategies for the inclusion of women in sport: The case of Norway. Sport in Society, 15, 287-301.

IWG. (2013). Greetings from President Halonen: Sport has the power to tell stories that stay in our minds and hearts. Retrieved from https://iwg--gti-org.directo.fi/catalyst/february2013/president-halonen-sport-has-the-/

Knights, D., \& Kerfoot, D. (2004). Between representations and subjectivity: Gender binaries and the politics of organizational transformation. Gender, Work and Organization, 11, 454-430.

Knoppers, A., \& Anthonissen, A. (2008). Gendered managerial discourse in sport organizations: Multiplicity and complexity. Sex Roles, 58, 93-103.

Lee-Gosselin, H., Briere, S., \& Ann, H. (2013). Resistances to gender mainstreaming in organizations: Toward a new approach. Gender in Management, 28, 468-485.

Martin, P. Y. (2003). 'Said and done' versus ‘saying and doing': Gendering practices, practicing gender at work. Gender \& Society, 17, 366-342.

McDowell, J., \& Schaffner, S. (2011). Football, it's a man's game: Insult and gendered discourse in the gender bowl. Discourse \& Society, 22, 547-564. 
McNae, R. (2010). Young women and the co-construction of leadership. Journal of Educational Administration, 48, 677-688.

McNay, L. (2000). Gender and Agency: Reconfiguration the Subject in Feminist and Social Theory. Cambridge, UK: Blackwell Publishers.

Moore, M. E., Parkhouse, B. L., \& Konrad, A. M. (2010). Women in sport management: Advancing the representation through HRM structures. Gender in Management, 25, 104 118.

Oakley, J. G. (2000). Gender-based barriers to senior management positions: Understanding the scarcity of female CEOs. Journal of Business Ethics, 27, 321-34.

O’Connor, V. J. (2001). Women and men in senior management: A "different needs" hypothesis. Women in Management Review, 16, 400-404.

O’Neil, D. A., Hopkins, M. M., \& Bilimoria, D. (2008). Women's careers at the start of the $21^{\text {st }}$ century: Patterns and paradoxes. Journal of Business Ethics, 80, 727-743.

Pfister, G. (2006). Gender issues in Danish sports organizations: Experiences, attitudes and evaluations. Nordic Journal of Women's Studies, 14, 27-40.

Pflieger, J., Fischer, M., Kupfer, T., \& Eyerer, P. (2005). The contribution of life cycle assessment to global sustainability reporting of organizations. Management of Environmental Quality, 16, 167-179.

Potter, J., \& Wetherell, M. (1987). Discourse and Social Psychology: Beyond Attitudes and Behaviour. London: Sage.

Powell, G. N. (2012). Six ways of seeing the elephant: The intersection of sex, gender, and leadership. Gender in Management, 27, 119-141. 
Powell, G. N., Butterfield, D. A., \& Parent, J. D. (2002). Gender and managerial stereotypes: Have the times changed? Journal of Management, 28, 177-93.

Roper, E. A. (2012). Together stronger: The future of sport. A review of the 5th World Conference of Women and Sport. Women in Sport \& Physical Activity Journal, 21, 7983.

Sartore, M. L., \& Cunningham, G. B. (2007). Ideological gender beliefs, identity control and semi-limited behavior within sport organizations. Quest, 59, 244-265.

Schein, V. E. (2007). Women in management: reflections and projections. Women in Management Review, 22, 6-18.

Sealy, R. (2010). Changing perceptions of meritocracy in senior women's careers. Gender in Management, 25, 184-197.

Shaw, S. (2001). The Construction of Gender Relations in Sport Organizations (Ph.D. thesis). Leicester, UK: De Montfort University.

Shaw, S., \& Frisby, W. (2006). Can gender equity be more equitable? Promoting an alternative frame for sport management research, education, and practice. Journal of Sport Management, 20, 483-509.

Shaw S., \& Hoeber L. (2003). A strong man is direct and a direct woman is a bitch: Gendered discourse and their influence on employment roles in sport organizations. Journal of Sport Management, 17, 347-375.

Shaw, S., \& Penney, D. (2003). Gender equity policies in national governing bodies: An oxymoron or a vehicle for change?. European Sport Management Quarterly, 3, 102-178. 
Shaw, S., \& Slack, T. (2002). It's been like that for donkey's years: The construction of gender relations and the cultures of sports organizations. Culture, Sport, Society, 5(2), $106-186$.

Spoor, J. R., \& Hoye, R. (2014). Perceived support and women's intentions to stay at a sport organization. British Journal of Management, 25(3), 407-424.

Tamir, I., \& Galily, Y. (2010). Women's sports coverage in Israel: Perception versus reality. International Journal of Sport Communication, 3(1), 92-112.

Thomas, M. M., \& Rugambwa, A. (2011). Equity, power, and capabilities: Constructions of gender in a Tanzanian secondary school. Feminist Formations, 23, 153-175.

Travers, A. (2009). The sport nexus and gender injustice. Studies in Social Justice, 2(1), 79101.

Whisenant, W. A., Pederson, P. M., \& Obenour, B. L. (2002). Success and gender:

Determining the rate of advancement for intercollegiate athletic directors. Sex Roles, 47, 485-91.

Yeganeh, H., \& May, D. (2011). Cultural values and gender gap: A cross-national analysis.

Gender in Management, 26(2), 106-21.

Zach, S. \& Adiv, T. (2015). Strength Training in Males and Females - Motives, Training Habits, Knowledge, and Stereotypic Perceptions. Sex Roles. DOI: 10.1007/s11199-0150544-3

\footnotetext{
${ }^{\mathrm{i}}$ The Centre for Young Talented Athletes (the Academy for Sport Excellence) was established in Israel in September 1990 to support talented young athletes in different sports with all available resources. From early on, it was a strong breeding ground for future elite Israeli athletes. The Centre (Academy) serves a limited number of sports and comprises young athletes from ages 12 to 18. Until the inauguration of the Volleyball Academy for Boys in 2002, the Centre historically comprised individual sports. The entrance of team sport changed the policy and opened up new opportunities.
} 
The first team sport to arrive was volleyball, with the establishment of the Boy's Academy and the establishment of the VAYTG a year later, in 2002. M led the initiative to establish the VAYTG throughout 2002. By then. she was an official who strove for the young female players to be given the opportunity to fulfill their potential.

ii The interviews were conducted by the same person who also wrote the auto-ethnography, Chang's (2008) warnings of pitfalls to avoid were carefully kept in mind: "(1) excessive focus on self in isolation from others; (2) overemphasis on narration rather than analysis and cultural interpretation; (3) exclusive reliance on personal memory and recalling as a data source; (4) negligence of ethical standards regarding others in self-narratives; and (5) inappropriate application of the label autoethnography" (Chang 2008:54).

iii It is not our intention to embroil on the feminism debate. We tend to agree with De Sensi (1982) that the term feminism, for both women and men, often involves a gross misrepresentation of its real nature and significance. Similarly, Burke (2001) asserts that there are diverse, divergent strands of thought and political action within the movement of loosely collected traditions that are considered feminist. In modern times, this problem of definition has spawned the acknowledgement of a variety of feminisms, including liberal feminism, radical feminism, black feminism, gay feminism, postmodern feminism, and existential feminism, among others. These groups are all concerned with improving the position of women in society. For further readings, see Dewar (1993). 